\title{
Caracterización del ejercicio periodístico en los debates presidenciales chilenos: una comparación entre mujeres y hombres en su rol como entrevistadores
}

\author{
Characterization of the journalistic exercise in Chilean \\ presidential debates: a comparison between women and men in \\ their role as interviewers
}

\author{
Ortega-Gunckel, C., Proust, V. y Porath, W.' \\ Recibido: 24-09-2020 - Aceptado: 26-01-2021 \\ https://doi.org/10.26441/RC20.1-2021-A9
}

RESUMEN: La siguiente investigación presenta los resultados de un estudio mixto de carácter exploratorio, cuyo objetivo es identificar si las características del ejercicio periodístico se ven influidas por el enfoque de género, en el contexto de los debates presidenciales chilenos. Como corpus de análisis, se utilizaron las transcripciones de siete debates presidenciales televisados, organizados por ANATEL (Asociación Nacional de Televisión), emitidos entre los años 1989 y 2017.

A partir de un análisis de contenido realizado a 758 enunciados (emitidos por 13 periodistas mujeres y 22 hombres) y un análisis de comparación constante, se pudo identificar que, al contrario de lo que describe la teoría, las periodistas se comportan de manera similar a sus pares masculinos, construyendo sus preguntas principalmente sobre temáticas hard news, enfocándolas en torno a la ejecución y financiamiento de políticas públicas y respaldándolas con el uso de datos. Además, se observa que adoptan un rol cívico-perro guardián, respondiendo a las expectativas tradicionales en torno al ejercicio del periodismo; en cambio, los hombres adoptan un rol cívico-antagónico. Se concluye que los debates, al ser una instancia neutral con reglas preestablecidas, disminuye la inequidad y desigualdades entre periodistas según su género, reduciendo las barreras existentes en las salas de redacción.

Palabras clave: debates electorales televisados; género; roles periodísticos.

ABSTRACT: The following research presents the results of a mixed exploratory study, whose objective is to identify if the characteristics of the journalistic exercise are influenced by the gender approach, in the context of the presidential debates carried out in Chile. As a corpus of analysis, the transcripts of seven televised presidential debates, organized by ANATEL (National Television Association) and broadcast between 1989 and 2017, were used.

Based on a content analysis of 758 statements (broadcast by 13 female and 22 male journalists) and constant comparison analysis, it was possible to identify the following: contrary to what the theory describes, female journalists behave similarly to their male peers, constructing their questions mainly on

\footnotetext{
${ }^{1}$ Constanza Ortega-Gunckel es Magíster en Psicología con mención en Psicología Comunitaria por la Universidad de Chile, Cientista Política y Asistente de investigación en la Facultad de Comunicaciones de la Pontificia Universidad Católica de Chile. cortega1@uc.cl, http://orcid.org/0000-0001-9182-3827

Valentina Proust es Periodista, Licenciada en Letras Hispánicas e Instructora adjunta en la Facultad de Comunicaciones de la Pontificia Universidad Católica de Chile. vsproust@uc.cl, https://orcid.org/0000-0002-3648-4647

William Porath es Doctor en Ciencia Política por la Johannes Gutenberg Universität (Alemania), Periodista y Profesor Titular en la Facultad de Comunicaciones de la Pontificia Universidad Católica de Chile. wporath@uc.cl, https://orcid.org/0000-0003-0677-2928
} 
challenging news topics, focusing them on the execution and financing of public policies, and supporting them with the use of data. Also, they adopt a civic-guard dog role, responding to traditional expectations regarding the exercise of journalism; in contrast, men assume a civic-antagonistic role. In conclusion, the debates, being a neutral instance with pre-established rules, diminish the inequity and inequalities among journalists according to their gender, reducing the existing barriers in the newsrooms.

Keywords: televised election debates; gender; journalistic roles.

\section{Introducción ${ }^{2}$}

Si bien a lo largo de todo el siglo XX las mujeres comenzaron a incorporarse de manera cada vez más masiva a las salas de redacción, se considera que el periodismo continúa siendo un área marcadamente masculina (Djerf-Pierre, 2011). En gran parte del mundo el porcentaje de mujeres que trabajan en medios de comunicación es significativamente menor en comparación a los hombres, alcanzando cifras dramáticas en zonas de Asia y Medio Oriente, con poco más del 15\% de representación (Byerly, 2013).

En el caso de América Latina, cinco países presentan una relación 2:1 entre periodistas hombres y mujeres: Argentina, Chile, Costa Rica, República Dominicana y Ecuador (Byerly, 2011). Esta inequidad en la participación de mujeres y hombres en los medios de comunicación ha levantado la pregunta sobre los efectos que puede tener la variable género en la entrega de la información. Por una parte, existe una corriente que postula que el género no es un factor que influya en el ejercicio de la profesión, ya que el periodismo sería un trabajo neutro (Hanitzsch y Hanusch, 2012).

Pero, por otra parte, distintas investigaciones han puesto énfasis en las diferencias que se producen en los temas, ángulos, el uso de fuentes y la ética, dependiendo del género del periodista (Van Zoonen, 1998; Everbach y Flournoy, 2007; Ruoho y Torkkola, 2018). Siguiendo esta última postura, se considera que las desigualdades y la inequidad de género al interior de los medios se refleja en diferencias en cuanto a las actitudes en el ejercicio del periodismo. Particularmente, en lo que se refiere a la cobertura de las hard news y las soft news, el rol de las periodistas en la sala de prensa y el foco que ponen en la noticia.

Esto lleva al cuestionamiento sobre si, en un contexto con igualdad de condiciones y exigencias para periodistas hombres y mujeres, se manifiestan diferencias en las prácticas periodísticas de acuerdo con el género. En esta línea, surge la pregunta sobre cuáles son las características del ejercicio periodístico que se ven influidas por un enfoque de género.

Teniendo en cuenta lo anterior, esta investigación propone un estudio sobre las actitudes en el ejercicio periodístico en un contexto neutro y sin mediación de género, como lo son los debates electorales televisados con panel de periodistas (formato que se sigue utilizando en algunos países latinoamericanos, siendo Chile uno de ellos). La elección de esta instancia se debe a que se diferencia de otros discursos periodísticos por tener un carácter cívico, solemne (Coleman y Moss, 2016) y permitir que sean los entrevistadores quienes guíen la discusión, introduzcan temas y cuestionen a los candidatos (Eveland, McLeod y Nathanson, 1994).

Tomando en cuenta lo anterior, se plantea la siguiente pregunta de investigación: ¿cuáles son las características del ejercicio periodístico que se ven influidas por un enfoque de género en el desa-

\footnotetext{
2 Este artículo forma parte de los proyectos financiados por el Fondo Nacional de Desarrollo Científico y Tecnológico, FONDECYT, proyecto No 1170843. de la Agencia Nacional de Investigación y Desarrollo de Chile (ANID/ CONICYT).
} 
rrollo de los debates presidenciales? Y, como objetivo: se propone la identificación de las características del ejercicio periodístico que se ven influidas por un enfoque de género, en el contexto de los debates presidenciales televisados realizados en Chile. Para alcanzarlo, se plantean los siguientes objetivos específicos:

1. Caracterizar el estilo periodístico que es utilizado en la realización de preguntas en los debates presidenciales televisados.

2. Identificar el tipo de contenido que es cubierto por los periodistas en las preguntas realizadas durante el debate presidencial.

3. Identificar las semejanzas y diferencias en estilo y contenido entre los periodistas, de acuerdo con la variable de género.

Se propone la realización de una investigación de carácter mixto, desde una aproximación exploratoria, a partir del análisis de 758 unidades, que corresponden a las preguntas, contra-preguntas e intervenciones realizadas por los periodistas que participaron en los debates presidenciales televisados realizados entre 1989 y 2017 por la Asociación Nacional de Televisión de Chile (ANATEL). A partir de este análisis, se espera identificar si las prácticas periodísticas mencionadas en la literatura están o no presentes en los debates, como un contexto neutro para el ejercicio del periodismo, en donde las reglas se piensan sin considerar el género de sus participantes.

\section{Marco referencial}

\subsection{Mujeres y periodismo: una tradición de relaciones desiguales}

Ross y Carter (2011) indican que, a pesar del incremento en la presencia de mujeres en los medios de comunicación, no ha cambiado el escenario de la producción de noticias en lo que respecta a la desigualdad de género. No solo la representación de la mujer cae en estereotipos o se encuentra ausente en los artículos, sino que todavía perdura una brecha de género en el periodismo, que impide que las periodistas puedan ejercer su trabajo de la misma manera que los hombres (Byerly, 2013).

Entre los factores que terminan por hacer más difícil la participación de la mujer en las salas de prensa, se encuentra la necesidad de compatibilizar el tiempo de trabajo con la familia; carga que ha sido puesta socialmente en el género femenino. Lo anterior, sumado a los bajos sueldos y a las largas jornadas, hace más compleja la situación y dificulta su permanencia en los medios (Everbach y Flournoy, 2007). A esto se suman los procesos sociales, históricos y culturales de cada país, que pueden intensificar aún más la brecha. Por ejemplo, en Asia, Medio Oriente y América Latina, zonas donde predomina una cultura machista, hay una participación significativamente menor de mujeres en los medios de comunicación (Byerly, 2011). Este machismo, marcado por la entrega de un mayor poder al hombre en la sociedad, dificulta el acceso a las mujeres a espacios de toma de decisión y opinión (Felitti y Rizzotti, 2016), lo que se ve reflejado en su participación en los medios.

Como consecuencia de lo anterior, no solo los medios cuentan en proporción con menos mujeres, sino que también se produce el fenómeno denominado como "tejado de vidrio", entendido como la barrera simbólica que impide que las periodistas puedan llegar a puestos de mayor jerarquía al interior de estas industrias (Chambers, Steiner y Fleming, 2004; Everbach y Flournoy, 2007). Esto provoca que las mujeres se encuentren ausentes en la toma de decisiones editoriales y gerenciales, causando una desigualdad vertical (North, 2016). Producto de esto, los medios son considerados ambientes masculinos, ya que la agenda, las prácticas y las rutinas de la profesión, están marcados por la perspectiva e intereses de este género (Ross, 2001). 
Van Zoonen (1998) explica que, gracias a este ambiente de desigualdad de género, las mujeres deban ajustarse a "reglas no escritas" para cumplir con las expectativas que se espera de ellas en este contexto. Por lo tanto, para ser validadas y valoradas, las periodistas tienden a imitar los comportamientos de sus pares masculinos y a auto exigirse más que ellos, reforzando la brecha de género. Siguiendo esta línea, se observa que tanto el comportamiento de las periodistas como los temas en los que las mujeres son protagonistas, se encuentran sujetos a un mayor análisis y escrutinio que sus pares masculinos. Bajo el dilema damned if you do, damned if you don't, las profesionales -y las mujeres en generalterminan recibiendo una mayor atención respecto a su comportamiento $\mathrm{y}$, en muchos casos, siendo juzgadas bajo un sesgo inconsciente que refleja y refuerza los valores culturales dominantes de una sociedad patriarcal (Peake, 1997) regida por normas masculinas (Gidengil y Everitt, 2000).

Ante esta desigualdad de condiciones en el rubro, se propone la concepción de un periodismo con enfoque de género, bajo el cual se busca analizar si el ejercicio de la profesión afecta de manera diferente a hombres y mujeres, tomando en cuenta la construcción social en torno a los géneros y sus roles (Chaher y Santoro, 2007). Si bien hay autores que señalan que existen factores que influyen más que el género en el ejercicio de las prácticas periodísticas, como por ejemplo la experiencia de reporteo en terreno (Hanitzsch y Hanusch, 2012), existe una línea de investigación que analiza las manifestaciones de la desigualdad de género en las salas de redacción (Van Zoonen, 1988; Everbach y Flournoy, 2007; Ruoho y Torkkola, 2018). Estas desigualdades se pueden resumir en tres puntos: el rol de la mujer periodista, las temáticas noticiosas y el enfoque que se da a la noticia.

\subsubsection{Rol de la mujer}

Jenkins y Finneman (2018) han planteado que el ejercicio periodístico de las mujeres en los medios replica los roles de una sociedad heteronormativa. Producto de esto, las periodistas ven limitadas sus posibilidades de desarrollo al interior de la sala de redacción, ya que deben acomodarse a la cultura masculina del medio para ser valoradas por sus pares. Algunos teóricos (vg. Van Zoonen, 1988) explican que, de aumentar la presencia de mujeres en los medios, especialmente en cargos de toma de decisiones editoriales, podría cambiar el rol de la mujer y cómo es valorada. Mientras se espera que los periodistas "hagan una diferencia" a través de su reporteo, de las periodistas solo se espera que sean capaces de legitimar su lugar en la esfera pública (Djerf-Pierre, 2011).

\subsubsection{Temáticas noticiosas}

En el periodismo se diferencian dos tipos de noticias: hard news y soft news (Tuchman, 1978 citado por Weischenberg, 1992). Por una parte, las hard news se asocian con la representación factual de acontecimientos que son considerados con valor noticioso, como política, internacional o economía. Por otra parte, las soft news suelen relacionarse a temas que no son de publicación urgente, sin un valor informativo tan potente como las hard news, con un enfoque en historias de interés humano: sociedad, espectáculo, cultura, etc.

Esta diferencia no solo tiene consecuencias en el valor que se le da en la agenda a una noticia, ya que tradicionalmente se asocia que las periodistas cubren soft news y sus pares masculinos las hard news (North, 2016). Con esta perspectiva, se ha establecido la diferencia entre un aparente periodismo masculino y uno femenino. Franks (2013) explica que esta segmentación de temáticas provoca la construcción de pink ghettos, relegando a las periodistas a la cobertura de soft news. En esta línea, Amado (2017) explica que se suele asociar a las soft news con noticias con perspectiva de género. Si bien se pueden encontrar cada vez más mujeres cubriendo noticias relacionadas con política o deporte (temas tradicionalmente masculinos), continúa existiendo un estereotipo cultural sobre los frentes informativos (North, 2016), ya que se siguen prefiriendo a los periodistas hombres para cubrir estos temas. 


\subsubsection{Enfoque de la noticia}

De la misma manera que se asocian temáticas noticiosas de acuerdo con el género del periodista, también se ha establecido una diferencia en el enfoque que se le da a la información, dependiendo de si el periodista es hombre o mujer. Van Zoonen (1998) señala que las periodistas tienden a inclinarse hacia las necesidades de la audiencia y presentan un mayor involucramiento emocional con la información. En consecuencia, presentan las noticias con un enfoque en lo "humano" y usan un tono más íntimo (Schoch, 2013). De esta forma, Christmas (1997) indica que las periodistas humanizan las noticias, con el fin de que los lectores y audiencias puedan identificarse con ellas y considerarlas relevantes. En cambio, los periodistas se enfocan principalmente en la entrega de datos, sin considerar el factor humano.

\subsection{Mujeres y periodismo en Chile}

Al igual que en gran parte de América Latina, en Chile las mujeres ocupan un espacio reducido en las salas de redacción, representando el 39\% de la fuerza de trabajo. Esta cifra es aún más dramática en los medios que no pertenecen a la capital del país, donde alcanza apenas el 30,6\% de los puestos de trabajos (Lagos y Mellado, 2013). Por lo tanto, aproximadamente dos de cada tres periodistas en Chile son del género masculino (Leiva y Kimber, 2020). Si bien estas cifras representan un aumento en relación a las décadas anteriores al 2010, donde las mujeres participaban considerablemente menos en los medios, su figura continúa siendo marginalizada. Por ejemplo, en lo que respecta a la participación en los altos cargos al interior de los medios de comunicación, la ocupación de mujeres sólo alcanza 8,6\% (Lagos y Mellado, 2013).

En lo que respecta a las prácticas y rutinas periodísticas de acuerdo al género en Chile, no se han desarrollado investigaciones que determinen en profundidad las diferencias entre hombres y mujeres en la sala de redacción. Las investigaciones realizadas se han centrado en la presentación de lo femenino y el rol de la mujer en los medios (v.g. Salinas y Lagos, 2013) o abordan de manera general el contexto de trabajo en estos espacios. Por lo anterior, se ha señalado que la producción de noticias en Chile se ha rendido al sistema del mercado de medios, transformando el reporteo en una actividad mecanizada y automatizada, que uniforma a los periodistas (Stange y Salinas, 2015); homogeneidad que se ve intensificada por la digitalización del trabajo, que lleva a que los temas y las fuentes sean semejantes (Gronemeyer, 2013). Además, se observa una marcada concentración y centralización de los medios y el trabajo periodístico en la capital del país (Mellado, Salinas, Del Valle y González, 2010), sumada a los escasos puestos de trabajo producto de la rigidez del sistema (Mellado, Salinas y Barría, 2010). Todo lo anterior, son los antecedentes en los que se enmarca la participación de las mujeres en las salas de redacción.

\subsection{Debates}

Los debates televisados, en tiempos de desafección política, se han transformado en una forma eficaz de llegar a la ciudadanía y proporcionar información acerca de temas políticos (García Marin, 2013). Esto, no solo los ha posicionado como uno de los eventos más importante de las campañas políticas, sino que ha despertado el interés de diversos investigadores (Luengo, 2011; Rúas-Araújo y Quintas-Froufe, 2020), que han encontrado en los debates una oportunidad para estudiar discursos, conductas, estrategias y performance.

Hoy, estos espacios se presentan como arenas híbridas, en donde el sistema político y el sistema de medios pueden interactuar bajos sus propias reglas (Echeverría, 2008, p.115), posibilitando la investigación de conductas y prácticas de sus participantes en un ambiente controlado, donde muchas de las rutinas políticas y periodísticas tradicionales son limitadas por normas particulares. 
Por esta razón, los países que utilizan el formato panel de periodistas (como Chile) se presentan como un objeto de estudio interesante, ya que permiten investigar el comportamiento de estos profesionales, en un ambiente donde las rutinas que se observan en las salas de prensa se ven supeditadas por las normas previamente acordadas para el debate. Asimismo, permiten ver las formas en que los periodistas guían la discusión, presentan los temas e interpelan a los candidatos (Eveland, McLeod y Nathanson, 1994) por medio de una serie de roles que se diferencian de otras instancias mediáticas como noticias y entrevistas.

Según Núñez-Mussa (2019), los periodistas que participan de los debates electorales televisados realizan sus preguntas desde cuatro roles, siendo el primero el rol Cívico, con el que el periodista representa las preocupaciones y puntos de vista de la sociedad en su diversidad (Pellegrini et al., 2011). Por medio del segundo rol, Perro Guardián, se fiscaliza al candidato para determinar qué tan idóneo es este para un cargo público (Sjøvaag, 2010). En el tercer rol, Antagónico/Adversario, el/la periodista expone los defectos del candidato con "cinismo" y/u hostilidad, dando a conocer acciones pasadas, errores y defectos sin relacionarlos con la posibilidad de que sea presidente (Casero, 2008). Y, por último, bajo el rol Estratégico/Carrera de caballo se enfoca en la cobertura de la campaña y de los procesos organizativos y las normas periodísticas (Iyengar, 2011).

Respecto a los temas que pueden ser abordados durante el debate, según Benoit (2003) estos pueden ser considerados bajo dos grandes categorías: políticas públicas (junto con proyectos asociados a ellas) y el carácter (o imagen) del candidato. Específicamente, Benoit y Harthcock (1999, p.346) definen los temas de políticas públicas como toda acción gubernamental (acciones pasadas, objetivos generales y planes futuros). Por su parte, el carácter es entendido como las capacidades de liderazgo que tiene la o el candidato, así como los aspectos relacionados con su personalidad; cuando se abordan temas de esta naturaleza se observan cualidades personales, habilidades e ideales.

En cuanto a la forma de aproximarse a la información durante un debate, al igual que en medios, puede ser a través de opiniones y/o información objetiva (McQuail, 2000) que se presenta por medio del apoyo de diferentes puntos de vistas, declaraciones y, en algunos casos, la separación clara entre el contenido de la información y la opinión (Tuchman, 1978 citado por Weischenberg,1992).

\subsubsection{Debates y enfoque de género}

Si se observan las áreas temáticas en las que se ha focalizado la investigación que existe sobre debates electorales, esta se ha centrado principalmente en conocer los efectos que tienen este tipo de instancia sobre: la decisión de voto (Mullinix, 2015); el conocimiento y las preferencias de los temas presentados a lo largo de las respectivas campañas (Turcotte y Goidel, 2014; McKinney, Rill y Thornson, 2013); y la agenda-setting (Luengo, 2011), entre otros efectos. Asimismo, autores interesados en el tema han estudiado las dinámicas entre candidatos (Benoit, 2007), el uso de estrategias discursivas (Proust, 2018) y las formas en que el uso de Internet y sus plataformas se hacen presentes durante los debates (Saks et al., 2016; Pérez-Curiel y García-Gordillo, 2020). Y, si bien la variable género ha estado presente en varios de estos trabajos (vg. Fracchiolla, 2011), el tema como tal no ha sido tan estudiado, si se compara con los focos previamente mencionados.

Entre las investigaciones que existen sobre la presencia de mujeres en debates electorales, la gran mayoría se enmarca en el halo de trabajos más complejos, donde el foco está en su participación política o en la cobertura que reciben; enfatizando que las mujeres cuentan con más filtros que los hombres, y que la cobertura política tiende a marginar a las mujeres cuando no se ajustan a las normas masculinas tradicionales presentes en la arena política (Meeks, 2013 citado por Rodelo, 2016). Así, la mayoría de los estudios sobre debates televisados bajo un enfoque de género son sobre las candidatas y los tipos de discursos que utilizan (Johnson, 2005), el carácter de la comunicación con 
la que se presentan -es decir, si son femeninos o masculinos-(Grebelsky-Lichtmana \& Kast, 2018), los tipos de performances con que se desenvuelven (Greenwood \& Coker, 2017) y las estrategias a las que recurren (McKinney \& Banwart, 2005; Maier \& Renner, 2018).

Por su parte, la investigación que existe sobre la participación de periodistas es aún más limitada. Turcotte y Paul, en 2015, encontraron que el género del periodista -en los debates presidenciales estadounidenses- está relacionado a la agenda que utilizan estos profesionales para presentar sus preguntas; así, las mujeres periodistas tienden a enfocar más sus preguntas a temas relacionados con la mujer en comparación con sus compañeros masculinos.

\subsubsection{Debates en Chile}

Pese a lo esperado, en Chile tras el plebiscito de 1989 se dio un ambiente propicio para el desarrollo del primer debate post dictadura en el país, tomando como base el modelo americano (Marín, 2003) utilizado en el debate entre Nixon y Kennedy.

El siguiente debate se realizó el año 1993 utilizando el mismo modelo, pero con una serie de modificaciones que permitieron la inclusión de preguntas realizadas por el público. En esta oportunidad el debate fue organizado por Asociación Nacional de Televisión (ANATEL) y fue la base para el debate de 1999, el cual contó con tres bloques, la participación de los dos participantes con mayor probabilidad de ser electos y el panel de periodistas encargado de hacer las preguntas correspondientes (Porath et al., 2019).

Las siguientes elecciones, en 2005, marcaron un antes y un después, no sólo porque en esta oportunidad participaron todos los candidatos a la presidencia (lo que supuso un cambio importante, porque de dos candidatos pasaron a ser cuatro), sino, además, porque por primera vez se realizaron dos debates (de primera y segunda vuelta). Estos cambios se mantendrían en 2013 y 2017, donde a pesar de que la distribución de los tiempos y módulos se mantuvo, se definió como norma que los debates estarían protagonizados por todos los candidatos inscritos oficialmente en la carrera presidencial, un panel de periodistas y se contaría con una primera y segunda vuelta (Porath et al., 2019).

Con respecto a la participación femenina en el panel de periodistas, se observa una situación similar a la de las salas de prensa ya que solo un $37 \%$ de los periodistas (35 en total) que participan en debates son mujeres. Esto probablemente se debe a que no existen cuotas de género que regulen su participación en esta instancia, ya que lo que importa es el canal que representan.

\section{Metodología}

Para lograr el objetivo propuesto se decidió trabajar con una aproximación exploratoria mixta para analizar todas las preguntas realizadas por los periodistas que participaron en los siete debates organizados entre 1989 y 2017 por la Asociación Nacional de Televisión (ANATEL). Del total, se identificaron 758 unidades de análisis, realizadas por 35 periodistas (13 mujeres y 22 hombres) a 31 candidatos (6 mujeres y 25 hombres).

El análisis de datos se realizó, por una parte, de forma cuantitativa, a través de un análisis de contenido de las preguntas realizadas por los periodistas. En este análisis se observó el tipo de interacción por género de acuerdo a los temas tratados en los enunciados, distinguiendo el tipo de unidad de análisis, compuesta por: preguntas (interacciones que inician la discusión y que se estipulan por reglas), contra preguntas (preguntas que se hacen una vez que el candidato responde la pregunta que abre el debate para aclarar o profundizar algo de lo dicho) e intervenciones (toda interacción en la que el periodista acota algún tipo de información, sin preguntar). 
La prueba de confiabilidad final, efectuada a 97 preguntas, arrojó un índice de coincidencias de .995 para la variable tipo de unidad de análisis (Kappa promedio $=.991)$.

Por otra parte, el análisis cualitativo se llevó a cabo por medio del método de comparación constante (Glaser y Strauss, 1967), que consiste en el desarrollo de conceptos por medio de la codificación y el análisis simultáneo de las unidades seleccionadas. Los conceptos que surgen son comparados sistemáticamente con el propósito de explorar las propiedades, relaciones, similitudes, diferencias, etc. que puedan existir entre las unidades. Una vez que la información es analizada, se busca integrar los hallazgos a una teoría coherente (Glaser y Strauss, 1967). Respecto a la codificación de los datos se hizo una vez que los debates fueron transcritos por medio de una sistematización abierta, axial y selectiva. Es decir, primero se identificaron los conceptos más recurrentes en las preguntas que estuvieran relacionados con la investigación, y luego se profundizó en sus propiedades y dimensiones, para así establecer nuevas categorías (Flick, 2004).

Para evitar sesgo de género, en la parte cuantitativa se trabajó con un grupo mixto de codificadores (1 hombre y 3 mujeres), quienes realizaron el análisis de contenido. En el caso de la sección cualitativa, esta fue realizada por los autores del estudio, quienes realizaron el análisis sin saber el género de las y los periodistas que participaron de cada debate.

\section{Análisis de los resultados}

\subsection{Análisis cuantitativo de la muestra}

Con el fin de alcanzar los objetivos planteados en esta investigación, a partir del contenido realizado a 758 unidades de análisis fue posible observar por género las dinámicas con que interactuaron los y las periodistas en cada debate. Pero, debido a que Chile nunca ha tenido un debate electoral televisado que sea igual al otro, al observar la Tabla 1 se debe tener en consideración una serie de aspectos antes de analizar los resultados. En primer lugar, solo tres de siete debates contaron con una participación equitativa de periodistas en cuanto a su género. En segundo lugar, es importante señalar que en el debate del año 2005 no participaron mujeres periodistas, siendo el único debate con esta característica -esta decisión no respondió a ninguna razón de género ni de discriminación, ya que estuvo relacionada a circunstancias de la organización de otros debates en paralelo-. En tercer lugar, dependiendo del formato del debate, la manera de interactuar de los periodistas cambia, puesto que, por ejemplo, en los debates de 1989, 1993, 2013 y 2017 podían preguntar, contra-preguntar e intervenir, mientras que en 1999, 2005 y 2009 contaban con una menor libertad.

Con respecto a los resultados del análisis de contenido, dado que las mujeres no participaron en todos los debates, no es posible establecer un patrón a lo largo del tiempo de manera ininterrumpida. Ahora bien, al observar los debates en que sí participaron periodistas de género femenino, es posible ver que, en comparación a sus compañeros masculinos, sus frecuencias de interacciones son menores ( $\mathrm{N}=\mathrm{M}: 37 \%$; $\mathrm{H}: 63 \%$ ), salvo en 2013, donde contra-preguntaron ( $\mathrm{N}=\mathrm{M}: 54 \%$; $\mathrm{H}: 46 \%$ ) e intervinieron $(\mathrm{N}=\mathrm{M}: 68 \% ; \mathrm{H}: 32 \%)$ más que el género masculino.

Sin embargo, pese a lo anterior, al ajustar las frecuencias y ponderarlas por el número y género de los participantes, se pudo observar que en los debates donde el número de participantes era equitativo por género, los periodistas participaron más que las periodistas. Mientras que, en los debates donde el número de periodistas mujeres era menor, estas preguntaron, contra-preguntaron e intervinieron mucho más que sus compañeros masculinos.

Esto se puede ver con mayor detalle en los debates de 1993, 2009 y 2017. En el primer debate, a pesar de que la frecuencia de intervenciones es la misma por género, al ponderar el número de pe- 
riodistas, se puede ver que las mujeres preguntaron (34\% vs un $23 \%)$, contra-preguntaron (15\% vs $10 \%$ ) e intervinieron ( $11 \%$ vs $8 \%$ ) en más ocasiones. En el caso del año 2009 , donde el número de interacciones no es el mismo y la proporción de periodistas es 1:4, las periodistas volvieron a intervenir proporcionalmente más. Por último, en 2017, pese a que no preguntaron más, en un contexto donde participaron 6 candidatos y 2 candidatas las periodistas intervinieron ( $8 \%$ vs $6 \%$ ) proporcionalmente más que sus compañeros.

Tabla 1. Resultados del análisis cuantitativo

\begin{tabular}{|c|c|c|c|c|c|c|c|c|c|}
\hline \multirow{3}{*}{$\begin{array}{l}\text { Tipo de } \\
\text { interacción }\end{array}$} & \multirow{3}{*}{\multicolumn{2}{|c|}{ Género }} & \multicolumn{7}{|c|}{ Año } \\
\hline & & & 1989 & 1993 & 1999 & 2005 & 2009 & 2013 & 2017 \\
\hline & & & & (H:S; MH:L) & (H:S; Мा:S) & (n:4) & (H:4; MV:I) & (H:S; IVI:S) & (H:2; M:1) \\
\hline \multirow{6}{*}{ Pregunta } & \multirow{2}{*}{ Mujeres } & $\mathrm{N}$ & 11 & 18 & 7 & 0 & 15 & 27 & 26 \\
\hline & & $\%$ & $22 \%$ & $28 \%$ & $44 \%$ & $0 \%$ & $14 \%$ & $11 \%$ & $12 \%$ \\
\hline & & $\%(a)$ & $22 \%$ & $34 \%$ & $44 \%$ & $0 \%$ & $32 \%$ & $11 \%$ & $18 \%$ \\
\hline & Hombres & $\mathrm{N}$ & 14 & 18 & 8 & 8 & 50 & 44 & 77 \\
\hline & & $\%$ & $27 \%$ & $28 \%$ & $50 \%$ & $19 \%$ & $46 \%$ & $17 \%$ & $35 \%$ \\
\hline & & $\%(a)$ & $27 \%$ & $23 \%$ & $50 \%$ & $19 \%$ & $26 \%$ & $17 \%$ & $27 \%$ \\
\hline \multirow{6}{*}{$\begin{array}{l}\text { Contra- } \\
\text { pregunta }\end{array}$} & \multirow{2}{*}{ Mujeres } & $\mathrm{N}$ & 6 & 8 & 0 & 0 & 7 & 72 & 24 \\
\hline & & $\%$ & $12 \%$ & $13 \%$ & $0 \%$ & $0 \%$ & $6 \%$ & $28 \%$ & $11 \%$ \\
\hline & & $\%(a)$ & $12 \%$ & $15 \%$ & $0 \%$ & $0 \%$ & $15 \%$ & $28 \%$ & $17 \%$ \\
\hline & \multirow{2}{*}{ Hombres } & $\mathrm{N}$ & 10 & 8 & 0 & 32 & 23 & 61 & 67 \\
\hline & & $\%$ & $20 \%$ & $13 \%$ & $0 \%$ & $76 \%$ & $21 \%$ & $24 \%$ & $30 \%$ \\
\hline & & $\%(a)$ & $20 \%$ & $10 \%$ & $0 \%$ & $76 \%$ & $12 \%$ & $24 \%$ & $24 \%$ \\
\hline \multirow{6}{*}{ Intervención } & \multirow{2}{*}{ Mujeres } & $\mathrm{N}$ & 3 & 6 & 1 & 0 & 5 & 34 & 11 \\
\hline & & $\%$ & $6 \%$ & $9 \%$ & $6 \%$ & $0 \%$ & $5 \%$ & $13 \%$ & $5 \%$ \\
\hline & & $\%(a)$ & $6 \%$ & $11 \%$ & $6 \%$ & $0 \%$ & $11 \%$ & $13 \%$ & $8 \%$ \\
\hline & \multirow{2}{*}{ Hombres } & $\mathrm{N}$ & 7 & 6 & 0 & 2 & 8 & 16 & 18 \\
\hline & & $\%$ & $14 \%$ & $9 \%$ & $0 \%$ & $5 \%$ & $7 \%$ & $6 \%$ & $8 \%$ \\
\hline & & $\%(a)$ & $14 \%$ & $8 \%$ & $0 \%$ & $5 \%$ & $4 \%$ & $6 \%$ & $6 \%$ \\
\hline \multicolumn{2}{|l|}{ Total } & $N$ & 51 & 64 & 16 & 42 & 108 & 254 & 223 \\
\hline & & & \multirow[t]{3}{*}{$100 \%$} & $100 \%$ & $100 \%$ & $100 \%$ & $100 \%$ & $100 \%$ & $100 \%$ \\
\hline & & & & 26,67 & & & 47,25 & & 142,00 \\
\hline & & & & $100 \%$ & & & $100 \%$ & & $100 \%$ \\
\hline
\end{tabular}

Fuente: elaboración propia

\subsection{Análisis cualitativo de la muestra}

A partir del análisis del corpus de preguntas realizadas por todos los periodistas a los candidatos, se identificó la presencia de tres nodos que permiten dar cuenta de la manera en que estos profesionales desempeñan su trabajo: Tema (1456 menciones), Enfoque (639 menciones) y Rol (835 menciones). En el caso de Tema, debido a que abarca distintas dimensiones de la construcción de las preguntas, se dividió en dos subnodos: Área (731 menciones) y Contenido (725 menciones). 
Cabe destacar que los nodos encontrados en ningún caso son proporcionales a las unidades de análisis. Esto porque dentro de una unidad fue posible encontrar más de un nodo o en ciertos casos no se encontró ninguno. Por eso mismo, y porque no se utilizó un análisis de contenido cuantitativo, la elección de nodos no está hecha solo por la frecuencia, sino que también tienen en cuenta la bibliografía trabajada, el contexto en que se desarrollaron los debates y la relación de lo encontrado con temáticas de género. Teniendo en cuenta lo anterior, a continuación, se presentan las principales observaciones y hallazgos en relación con la manifestación de estos nodos en los debates, bajo una perspectiva de género (considerando el estilo de reporte de Greenberg et al. (1980)).

\subsubsection{Nodo Tema}

La presencia del nodo Tema se relaciona con las temáticas que abarcan las preguntas hechas por los y las periodistas hacia los candidatos. Este comprende dos dimensiones desde las que se construye el tema de la pregunta: por una parte, se encuentra el Contenido, que corresponde a los asuntos abarcados en las preguntas de los debates (si son acerca de políticas públicas o si se enfocan en el carácter del candidato); y por otra, está el subnodo Área temática, desde el que se observa si las preguntas corresponden, de acuerdo a la teoría (North, 2016), a un hard news o a un soft news.

\subsubsection{1. Área temática}

En los enunciados analizados se observa que, tanto periodistas mujeres como hombres, prefieren construir sus preguntas bajo áreas temáticas de las hard news (H: 380; M: 227), que las de las soft news (H: 86; M:38). Al observar la Tabla 2, estos resultados se contradicen con las descripciones hechas por la teoría (Franks, 2013), según las cuales las mujeres hubiesen tendido a utilizar más las soft news que las hard news. Por lo tanto, se puede pensar en el debate como un escenario neutro de ejercicio del periodismo, en el que se espera que todos los periodistas, sin importar su género, se hagan cargo de los temas hard news, rompiendo con las divisiones tradicionales en la sala de redacción. A esto, se puede sumar la interpretación de que las mujeres busquen validarse a sí mismas como profesionales, lo que incentivaría a que elaboren sus preguntas bajo el paradigma del ideal de periodista masculino (Van Zoonen, 1998).

A pesar de la similitud en cuanto a la elección de área temática, se identifica que la manera en que estas son empleadas varía de acuerdo al género. Por ejemplo, en su mayoría son las mujeres quienes plantean temas con enfoque de género (11 menciones): “A propósito de las mujeres... ¿Cuántas mujeres ocupan cargos de responsabilidad en sus empresas?" (ejemplo 1, debate 20093); "Revisé su programa y busqué propuestas para la mujer y no hay un capítulo específico que diga 'propuestas para la mujer', a diferencia de los otros candidatos, pero usted habla de la extensión del postnatal, del teletrabajo [...]" (ejemplo 2, debate 2009). En cambio, si bien los hombres también las incluyen, estas tienen menos apariciones (4 menciones) y solo se centran en la discusión en torno a la legalización del aborto.

En lo que respecta al uso de las soft news en las preguntas, estas tienen la particularidad de caracterizarse como tal no por el contenido de estas (noticias relacionadas con cultura, vida privada o entretenimiento), sino que es la manera en la que son presentadas: hay una tendencia al sensacionalismo o buscar generar polémicas en la manera en que se pregunta una información. Por ejemplo: "La señora Estela Ortiz, viuda de Parada, candidata a diputada que lo apoya a usted, en condiciones personales de extremo dolor, ha dicho que se imagina y quiere preso al general Pinochet ¿Usted también se lo imagina preso?" (ejemplo 3, debate 1989).

\footnotetext{
${ }^{3}$ Lista completa de ejemplos utilizados disponible en Anexo 1
} 
En este caso, se alude a temáticas relacionadas con la política nacional y la historia del país, pero son planteadas buscando opiniones de carácter polémico de parte del candidato.

Tabla 2. Resultados del análisis cualitativo - Área temática

\begin{tabular}{|ll|r|r|r|c|}
\hline \multirow{2}{*}{ Área temática } & \multicolumn{2}{|c|}{$f$} & \multicolumn{2}{c|}{$\%$} \\
\cline { 3 - 6 } & H & M & \multicolumn{1}{c|}{ H } & M \\
\hline \multirow{2}{*}{$\begin{array}{l}\text { Hard news } \\
\text { Soft news }\end{array}$} & 380 & 227 & $77 \%$ & $75 \%$ \\
\cline { 3 - 6 } & Enfoque de género & $\mathbf{8 6}$ & 38 & $18 \%$ & $12 \%$ \\
\cline { 3 - 6 } & & $\mathbf{4 9 0}$ & $\mathbf{3 0 5}$ & $\mathbf{1 0 0} \%$ & $\mathbf{1 0 0} \%$ \\
\hline Total & & & & & \\
\hline
\end{tabular}

Elaboración propia

\subsubsection{Contenido}

En lo que respecta al subnodo Contenido, se identifica que nuevamente hay un comportamiento similar en ambos géneros. Tanto los y las periodistas tienden a centrarse en contenidos relacionados con políticas públicas (H: 286; M:170), por sobre el carácter del candidato (H: 175; M: 94). Si se observa la Tabla 3 , se vuelve a contradecir la propuesta de la teoría, según la cual las mujeres tienden a abordar contenidos de interés humano y apelar a la intimidad (Schoch, 2013). En consecuencia, se refuerza la idea del debate como un espacio más neutral del ejercicio del periodismo y en el que las periodistas tienen más posibilidades para validarse a sí mismas como profesionales.

Si bien la cantidad de menciones por contenido es similar en cuanto al género del periodista, se identifican, nuevamente, diferencias en la manera en que estos son planteados. Por ejemplo, en preguntas sobre temas controversiales en la sociedad chilena, los hombres tienden a centrarse en el carácter del candidato: "Señora Miranda, para despejar cualquier duda en torno a lo que le preguntaba Soledad Onetto, ¿usted legitima o no legitima la violencia social como herramienta del acceso de las fuerzas populares al poder?" (ejemplo 4, debate 2013). En cambio, cuando estas temáticas son abordadas por las mujeres, tienen un enfoque desde las políticas públicas: “¿Un matrimonio igual que el matrimonio heterosexual, con los mismos derechos, por ejemplo, la posibilidad de adoptar niños?" (ejemplo 5, debate 2005).

Por otra parte, se observa que cuando los hombres plantean preguntas desde el carácter, apuntan a minimizar al candidato, particularmente cuando remiten a aspectos de la vida privada de este: "Senador Frei, qué piensa usted cuando lo tratan de Eduardito" (ejemplo 6, debate 1993). Este uso se identificó de manera muy mínima por parte de las periodistas mujeres (4 menciones), quienes optan por preguntar sobre la opinión del candidato respecto a alguna medida o evento.

Por último, en el caso de las preguntas sobre políticas públicas, destaca que las mujeres las tienden a enfocar en la ejecución y financiamiento sobre cómo se van a llevar a cabo estos cambios y propuestas:

"Señor Piñera, usted ha hablado del drama de los trabajadores. ¿Usted optaría por impulsar el salario mínimo, que hoy es de 123.000 pesos? A un chileno, con los descuentos de imposiciones, le quedan 98.000 pesos. De ello un tercio se va en gasto a movilización. '¿Usted sabe cuánto cuesta el nuevo transporte, bonito ese, del Transantiago, cuánto es el valor que cuesta?' " (ejemplo 7, debate 2005). 
En el caso de los hombres, si bien también se identifican preguntas con esta orientación, llama la atención que en ocasiones apuntan a las ideologías e ideales detrás de esas políticas públicas:

"Usted ha señalado que eh... Se requiere dignificar la política. Pero ¿se logra esto cuando usted trata, por ejemplo, a las mujeres de sus contendores como "escorts" o bien el comando o representantes de su comando, y usted particularmente, como conejitas playboy? ¿Se dignifica la política?” (ejemplo 8, debate 2013).

Tabla 3. Resultados del análisis cualitativo - Contenido

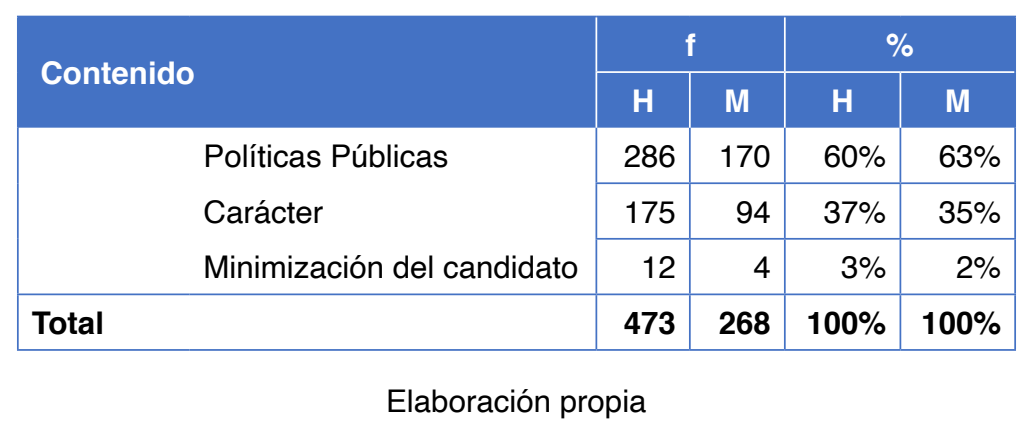

\subsubsection{Enfoque}

El nodo Enfoque tiene relación con la forma en que los periodistas se aproximan a la información al momento de hacer las preguntas. Este nodo comprende el uso de información objetiva -entendida como datos- $\mathrm{y}$ los acercamientos a través de opiniones emotivas.

Como muestra en la Tabla 4, tanto el uso de datos (412 menciones), como el uso de opiniones emotivas (227 menciones) presentan diferencias por género. En el caso de la mayoría de preguntas realizadas por hombres, no existe una separación entre el uso de información objetiva (259 menciones) y la opinión (153 menciones), ya que se suelen realizar preguntas en donde los datos duros se presentan como un complemento de lo emocional (180 menciones). Esto se puede ver en el siguiente ejemplo:

"Señor Guillier, anoche en un programa de televisión -ya lo comentó- habló de un spot que usted hizo el 2006 explicando las cualidades de las isapres, dijo que en ese tiempo estaba convencido que eran buenas pero que después quitaron beneficios y comenzaron con los abusos, pero para esa fecha usted ya había sido conductor de noticias, director de prensa, estuvo en Tolerancia Cero, presentó Informe Especial ¿No escuchó nunca hablar de la discriminación de los planes de la mujeres, de las preexistencias, de las alzas unilaterales?" (Ejemplo 9, debate 2017).

En cambio, las periodistas (a diferencia de sus compañeros) suelen preguntar utilizando datos duros como los ejes articuladores de la pregunta ( 153 menciones) por sobre lo emocional ( 71 menciones). Por ejemplo:

"Usted ha dicho que se pueden ahorrar 7 mil millones de dólares sacando lo que usted ha denominado "la grasa del Estado", algo que el ministro Nicolás Eyzaguirre le debatió ayer a través de la prensa diciendo coloquialmente "cuéntame una de vaqueros" pero lo cierto es que en el análisis de los expertos y los economistas ese monto no se logra si es que solo se recortan viáticos o gastos menores. La pregunta es muy concreta ¿Cuáles son los programas que se van a eliminar para obtener este ahorro de 7 mil millones?" (Ejemplo 10, debate 2017)

Complementando lo anterior, cuando los periodistas masculinos preguntan sobre hard news, suelen incluir antecedentes de carácter emocional (95 menciones): 
"Marcel Claude, usted en otras entrevistas ha calificado el lucro ni siquiera como un valor humano, es un desvalor, ha dicho...¿Por qué le molesta tanto el lucro? ¿Qué le dice por ejemplo a los pequeños y medianos empresarios que lo están escuchando esta noche, que legítimamente hacen su negocio con el objetivo de obtener alguna ganancia, de obtener lucro? (Ejemplo 11, debate 2013)". Esta estrategia que se observa en menor medida, cuando periodistas femeninas realizan las preguntas (71 menciones). Lo que se observa como una práctica común -a lo largo de los años- es que las periodistas apelan a lo emocional cuando tratan temas con enfoque de género como aborto (24 menciones de mujeres vs 16 menciones de hombres) y derechos laborales ( 8 menciones de mujeres vs 4 menciones de hombres), entre otros.

Tabla 4. Resultados del análisis cualitativo - Enfoque

\begin{tabular}{|r|r|r|r|c|}
\multirow{2}{*}{ Enfoque } & \multicolumn{2}{|c|}{$\mathbf{f}$} & \multicolumn{2}{c|}{$\%$} \\
\cline { 2 - 5 } Datos (información objetiva) & H & M & H & M \\
\cline { 2 - 5 } Opiniones emotivas & 259 & 153 & $37 \%$ & $36 \%$ \\
\cline { 2 - 5 } Combinación & 153 & 71 & $22 \%$ & $16 \%$ \\
\cline { 2 - 5 } Hard news emocional & 95 & 105 & $25 \%$ & $24 \%$ \\
\hline Enfoque de género emocional & & & $13 \%$ & $16 \%$ \\
\hline Aborto & 16 & 24 & $2,5 \%$ & $6 \%$ \\
\cline { 2 - 5 } Temas laborales & 4 & 8 & $0,5 \%$ & $2 \%$ \\
\hline Total & $\mathbf{7 0 7}$ & $\mathbf{4 3 2}$ & $\mathbf{1 0 0} \%$ & $\mathbf{1 0 0} \%$ \\
\hline
\end{tabular}

Elaboración propia

\subsubsection{Rol}

Teniendo en cuenta la propuesta de Núñez-Mussa (2018) se puede observar en la Tabla 5 que, del total de preguntas realizadas $(\mathrm{n}=758), 315$ se hicieron desde una perspectiva de un rol Cívico (H: 209; M: 103), 239 por medio del rol Perro Guardián (H: 136; M: 106), 230 bajo del rol Antagónico (H: 135; M: 95) y 51 desde el rol Carrera de caballo (H: 34; M: 17). Respecto al uso de estos roles, el análisis cualitativo mostró, en primer lugar, que los periodistas adoptan el rol Antagónico, pero lo utilizan como un complemento del rol Cívico y Perro guardián. Por lo tanto, tiende a presentarse de manera híbrida y no de manera pura, lo que lleva a pensar que se comporta más como un estilo que adopta el periodista que un rol.

En segundo lugar, se pudo ver que el uso de roles cambia por género. En el caso de los periodistas masculinos, estos tienden a preguntar por temas que son una preocupación para los espectadores en materia de políticas públicas, por lo que el rol que más utilizan es el Cívico bajo un encuadre Antagónico (103 menciones). Por ejemplo:

"Señora Matthei, emm... según la encuesta del CEP el 74\% de la gente quiere educación gratis. Es el dato duro que entregó hace poco el estudio. Usted ha reiterado que está en contra porque lo considera regresivo. En esa misma encuesta usted está, además, al borde de perder en primera vuelta esta elección. Me gustaría saber si usted está dispuesta a decirle que no en esta materia a 3 de 4 chilenos" (Ejemplo 12, debate 2013).

En cambio, bajo una concepción más idílica del rol del periodismo (Hanitzsch y Hanusch, 2012), las mujeres utilizan con mayor frecuencia el rol híbrido Perro guardián-Cívico ( 73 menciones), para fiscalizar si él o la candidata está preparado para asumir el cargo de Presidente. Por ejemplo: 
“Señor Enríquez Ominami, volvamos a la CEP, son los datos más actuales que tenemos. 83\% está por nacionalizar el cobre, tema de importancia para la opinión pública. Usted hace cuatro años propuso abrir parte de Codelco a la Bolsa, ¿no es así? Hoy habla de nacionalizar los recursos naturales. Asumiendo que todos tenemos derecho a cambiar de opinión, ¿qué pasó en el camino? ¿Por qué cambió de opinión?" (Ejemplo 13, debate 2013).

Por último, se observó que cuando los y las periodistas deben insistir en un tema, porque él o la candidata evade la pregunta, las periodistas nuevamente utilizan el rol Perro guardián (25 menciones), mientras que sus compañeros lo hacen a través del rol Antagónico (36 menciones) exponiendo los defectos del candidato con "cinismo" y/u hostilidad. En este punto es necesario agregar que las periodistas, a diferencia de sus pares masculinos, deben insistir con mayor frecuencia en que les respondan sus preguntas que los candidatos suelen evadir o desestimar el tema (66 menciones).

Tabla 5. Resultados del análisis cualitativo - Rol

\begin{tabular}{|c|c|c|c|c|}
\hline \multirow{2}{*}{ Rol } & \multicolumn{2}{|c|}{$f$} & \multicolumn{2}{|c|}{$\%$} \\
\hline & $\mathbf{H}$ & $\mathbf{M}$ & $\mathbf{H}$ & M \\
\hline Cívico & 209 & 103 & $29 \%$ & $20 \%$ \\
\hline Perro Guardián & 136 & 106 & $19 \%$ & $20 \%$ \\
\hline Antagónico & 135 & 95 & $19 \%$ & $17 \%$ \\
\hline Carrera de caballo & 34 & 17 & $5 \%$ & $3 \%$ \\
\hline Antagónico-Cívico & 103 & 27 & $14 \%$ & $4 \%$ \\
\hline Antagónico-Perro Guardián & 28 & 73 & $4 \%$ & $14 \%$ \\
\hline Perro Guardián en evasión & 12 & 25 & $2 \%$ & $5 \%$ \\
\hline Antagónico en evasión & 36 & 7 & $5 \%$ & $1 \%$ \\
\hline Insistencia & 21 & 66 & $3 \%$ & $16 \%$ \\
\hline Total & 714 & 519 & $100 \%$ & $100 \%$ \\
\hline
\end{tabular}

Elaboración propia

\section{Discusión y conclusiones}

Los estudios que se han realizado respecto al trabajo de los y las periodistas en las salas de redacción han enfatizado las diferencias que se producen en la construcción del discurso periodístico dependiendo del género del profesional (vg. Van Zoonen, 1998; Everbach y Flournoy, 2007; Ruoho y Torkkola, 2018). Sin embargo, el análisis realizado a las preguntas de los debates presidenciales chilenos da cuenta de que estas conductas estereotipadas no se manifiestan de la misma manera que en el discurso periodístico que ha sido investigado hasta el momento.

Por una parte, autoras como Franks (2013) y North (2016) han indicado que tradicionalmente son las mujeres quienes cubren soft news, mientras que los hombres suelen cubrir las llamadas hard news. Sin embargo, en los debates estudiados, las preguntas tienden a abarcar en su mayoría hard news, sin importar el género del periodista que la emite. En consecuencia, no se observa el sesgo descrito por las autoras. Donde sí se puede encontrar una diferencia en base al género es en la manera en la que se cubren las hard news: cuando las mujeres preguntan sobre temas de políticas públicas, estas ponen énfasis en la ejecución y financiamiento de las propuestas, mientras que los hombres se enfocan en el aspecto ideológico que hay detrás. Por lo tanto, se puede señalar que, en el caso de los debates chilenos, no hay presencia de los llamados pink ghettos (Franks, 2013). 
Se podría pensar que hay presencia de un purple ghetto ${ }^{4}$, ya que las periodistas, a diferencia de los hombres, se animan a preguntar por temas de interés para las mujeres y las causas feministas, replicando lo descrito por Turcotte y Paul (2005). Lo anterior se explica debido a que en el caso de los debates analizados, los temas para preguntar se encuentran acordados previamente por los organizadores de la instancia, por lo que tanto hombres como mujeres apelan a los mismos frentes. Esto reafirma la idea del debate como una instancia más neutra para el desarrollo del trabajo periodístico, donde el género del periodista no debería tener relevancia.

Por otra parte, la teoría indica que las periodistas tienden a enfocar sus reporteo en temas de carácter humano, apelando a un tono más íntimo y cercano, mientras que sus pares masculinos se centran en la entrega de datos duros (Christmas, 2017; Schoch, 2013). Nuevamente los debates demuestran ser un espacio en el que el discurso periodístico se manifiesta de forma distinta, ya que tanto hombres como mujeres utilizan preferentemente datos duros como eje para la construcción de sus preguntas. Incluso, se identifica que son los periodistas de género masculino quienes tienden a apelar más a la emoción y, en algunos casos, al sensacionalismo, apelando a la vida personal del candidato para humillarlo frente a la audiencia.

A pesar de que pareciera haber un comportamiento con más semejanzas que diferencias entre los y las periodistas -facilitado por el contexto de neutralidad del debate- las conclusiones a las que han llegado otros autores permiten inferir que esto puede deberse a una sobrecompensación de las mujeres para estar "a la altura" de la instancia. Como indica Van Zoonen (1998; 2000), las periodistas deben ajustarse a las normas tácitas de la profesión, por lo que, para ser valoradas y ganar validación en los medios, tienden a imitar los comportamientos asociados a los hombres. En el caso de los debates analizados se ve reflejado en la preferencia por el uso de las hard news y los datos duros como articuladores de las preguntas.

Lo anterior se observa además en los roles que las periodistas adoptan en los debates: se identificó que su rol suele enmarcarse entre el Cívico y el Perro guardián, caracterizado por aludir constantemente a datos objetivos para contextualizar las preguntas e intervenciones que tienen relación con políticas públicas y los proyectos de los candidatos. Esto marca una gran diferencia respecto a sus compañeros masculinos, quienes suelen realizar preguntas e intervenciones de forma antagónica, utilizando impresiones, opiniones, vivencias o juicios personales para llegar a conocer la opinión de los candidatos y posicionarse como el mejor profesional.

El análisis de los debates chilenos da cuenta de que, ante la neutralidad en las normas de debate, las mujeres tendrían más facilidades para validar su figura, adoptando las temáticas, enfoques y roles que tradicionalmente han sido asociados con los hombres (Chaher y Santoro, 2007; Djerf-Pierre, 2011). Sin embargo, en paralelo se observa que los periodistas, quienes ya tienen una posición validada socialmente, pueden aprovechar la elaboración de las preguntas para lucirse y engrandecer su figura como periodistas. En consecuencia, si bien hay más igualdad en las posibilidades de ejercer el periodismo, se observarían los efectos de un sistema continuo que inclina la balanza hacia el género masculino: mientras las periodistas se auto exigen más con el fin de ser valoradas en el ambiente, los hombres podrían utilizar estas instancias para sobresalir como profesionales. Esta lectura reafirma las observaciones de autores como Peake (1997) y Meeks (2013), quienes dan cuenta de los sesgos patriarcales bajo los cuales se analiza y critica el trabajo de los periodistas.

Si bien los debates terminan por replicar algunas de las lógicas y roles heteronormativos del discurso periodístico (Jenkins y Finneman, 2018), particularmente la autoexigencia de las periodistas, son la prueba de que cuando a las mujeres se le dan las mismas oportunidades que a sus pares masculi-

\footnotetext{
${ }^{4}$ Alusión al color morado como parte de los símbolos reconocibles en Chile del movimiento feminista.
} 
nos, pueden realizar la labor que se espera del periodismo como el cuarto poder y la voz del pueblo. La igualdad de condiciones, gracias a las reglas negociadas entre los organizadores, compensa su escasa presencia en los espacios de toma de decisión producto del llamado "tejado de vidrio" (vg. Ross y Carter, 2011; Felitti y Rizzoti, 2016) y la dificultad de compatibilizar los roles familiares que le han sido asignados (Everbach y Flournoy, 2007).

Por último, cabe destacar que, si bien el análisis permitió identificar las estrategias de trabajo de las periodistas en los debates presidenciales, se mantiene uno de los problemas identificados constantemente por la teoría: la cantidad considerablemente menor de periodistas mujeres en relación a sus pares masculinos (Byerly, 2011; 2013). En todos los debates realizados en Chile la cantidad de mujeres es escasa, ya que, al igual que en los medios de comunicación, no existe una cuota de género. Destaca particularmente el caso ya señalado del debate del año 2005, instancia en la que no participaron periodistas mujeres. Si bien la ausencia de mujeres puede responder a decisiones no relacionadas directamente con discriminación de género, esto podría -o no- dar cuenta de que de los canales no cuentan o piensan menos en periodistas mujeres al momento de elegir su rostro $\mathrm{u}$ "hombre ancla" para posicionarlo en el panel de periodistas, terminando por invisibilizar a las periodistas y reforzando los estereotipos que favorecen a las figuras masculinas.

\section{Limitaciones y proyecciones}

Entre las limitaciones de esta investigación se encuentra el que sólo se analizaron debates chilenos, por lo que no necesariamente responde a la realidad de todos los países, en los que el contexto de las problemáticas de género pueden ser muy diferentes. Además, sólo se consideraron los debates electorales de primera vuelta y no los de segunda vuelta. A esto se debe agregar que únicamente se consideraron los enunciados emitidos por los y las periodistas, sin considerar las respuestas que reciben de parte de los candidatos. Así como se observó que el género tiene incidencia en la manera que un periodista ejerce su profesión, se puede pensar que el género del candidato puede ser una variable que influya en su comportamiento. Particularmente, cuando se generan cruces entre periodista hombre-candidata mujer y periodista mujer-candidato hombre. Por lo tanto, dentro de las proyecciones de investigación, se encuentra estudiar si es que hay una mediación de género presente en las interacciones periodista-candidato.

Adicionalmente, se proponen dos líneas de investigación que pueden desarrollarse a partir de este trabajo. En primer lugar, los efectos que tiene la participación de las periodistas mujeres en la manera en que la audiencia percibe y entiende la representación de género. Y segundo, se puede desarrollar un estudio longitudinal para observar si es que ha habido alguna evolución respecto al desempeño y participación de las periodistas a lo largo de los debates. Este último punto no fue considerado para el desarrollo de esta investigación, ya que cada debate propone sus propias reglas y tienen dinámicas diversas, pero se puede construir una caracterización que permita compararlos y establecer un análisis de estas características. Además, tomando en cuenta que en el año 2005 no participaron periodistas mujeres en el debate, se dificulta poder identificar patrones o evoluciones a lo largo del tiempo.

\section{Bibliografía}

Amado, A. (2017). Las periodistas desde los estudios del periodismo: perfiles profesionales de las mujeres en los medios informativos. Cuestiones de género: de la igualdad y la diferencia, 12 , 325-346. https://doi.org/10.18002/cg.v0i12.4846

Benoit, W. L. (2003). Topic of presidential campaign discourse and election outcome. Western Journal of Communication (includes Communication Reports), 67(1), 97-112. https://doi. org/10.1080/10570310309374760 
Benoit, W. L., \& Harthcock, A. (1999). Functions of the great debates: Acclaims, attacks, and defenses in the 1960 presidential debates. Communication Monographs, 66, 341-357. https://doi. org/10.1080/03637759909376484

Byerly, C. M. (2013). Introduction. En Byerly, C.M. (Ed.) The Palgrave international handbook of women and journalism (pp.1-10). Springer.

Byerly, C. M. (2011). Global report on the status of women in the news media. Washington, DC: International Women's Media Foundation (IWMF). https://www.iwmf.org/wp-content/ uploads/2018/06/IWMF-Global-Report.pdf

Casero, A. (2008). Modelos de relación entre periodistas y políticos: La perspectiva de la negociación constante. Estudios sobre el Mensaje Periodístico 14, 111-128. https://revistas.ucm. es/index.php/ESMP/article/view/ESMP0808110111A

Chaher, S. y Santoro, S. (2007). La práctica del periodismo de género. Las palabras tienen sexo. Introducción a un periodismo con perspectiva de género. Artemisa Comunicaciones Ediciones.

Chambers, D., Steiner, L., \& Fleming, C. (2004). Women and journalism. Routledge.

Christmas, L. (1997). Chaps of Both Sexes?: Women Decision-makers in Newspapers: Do They Make a Difference?. BT Forum/ Women in Journalism.

Coleman, S., \& Moss, G. (2016). Rethinking election debates: What citizens are entitled to expect. The international journal of press/politics, 21(1), 3-24. https://doi. org/10.1177/1940161215609732

Djerf-Pierre, M. (2011). The difference engine: Gender equality, journalism and the good society. Feminist Media Studies, 11(01), 43-51. https://doi.org/10.1080/14680777.2011.537026

Echeverría V., M. (2008). Debates presidenciales y democracia en México. Desempeño de los candidatos en los debates presidenciales de 2006. Revista Mexicana de Ciencias Políticas y Sociales, 50(202), 33-49. https://doi.org/10.22201/fcpys.2448492xe.2008.202.42598

Eveland, W. P., McLeod, D. M. \& Nathanson, A. (1994). Reporters vs. undecided voters: An analysis of the questions asked during the 1992 presidential debates. Communication Quarterly, 42(4), 390- 406. https://doi.org/10.1080/01463379409369945

Everbach, T., \& Flournoy, C. (2007). Women leave journalism for better pay, work conditions. Newspaper Research Journal, 28(3), 52-64. https://doi.org/10.1177/073953290702800305

Fracchiolla, B. (2011). Politeness as a strategy of attack in a gendered political debateThe Royal-Sarkozy debate. Journal of pragmatics, 43(10), 2480-2488. https://doi.org/j. pragma.2011.02.006

Felitti, K. \& Rizzotti, A. (2016). El "machismo latinoamericano" y sus derivas en la educación internacional: reflexiones de estudiantes estadounidenses en Buenos Aires. Magis, Revista Internacional de Investigación en Educación, 9(18), 13-28. https://doi.org/10.11144/Javeriana. m9-18.mlde

Flick, U (2004). Introducción a la investigación cualitativa. Ediciones Morata.

Franks, S. (2013). Hard evidence: Is there still a gender bias in journalism. The Conversation. https://theconversation.com/hard-evidence-is-there-still-a-gender-bias-in-journalism-19789 
García Marín, J. (2013). Los debates electorales en televisión. En G. Óscar Luengo (Ed.), Medios y elecciones en España: la cobertura televisiva de la campaña de 2008. Editorial de la Universidad de Granada.

Gidengil, E., \& Everitt, J. (2000). Filtering the female: Television news coverage of the 1993 Canadian leaders' debates. Women \& Politics, 21(4), 105-131. https://doi.org/10.1300/ J014v21n04_04

Glaser, B., \& Strauss, A. (1967). El desarrollo de la teoría fundada. Chicago, EEUU: Aldine

Grebelsky-Lichtman, T., \& Katz, R. (2019). When a man debates a woman: Trump vs. Clinton in the first mixed gender presidential debates. Journal of Gender Studies, 28(6), 699-719. https://doi. org/10.1080/09589236.2019.1566890

Greenberg, B. S., Graef, D., Fernandez-Collado, C., Korzenny, F., \& Atkin, C. K. (1980). Sexual intimacy on commercial TV during prime time. Journalism Quarterly, 57(2), 211-215. https://doi. org/10.1177/107769908005700202

Greenwood, M. M., \& Coker, C. R. (2016). The political is personal: Analyzing the presidential primary debate performances of Hillary Clinton and Michele Bachmann. Argumentation and Advocacy, 52(3), 165-180. https://doi.org/10.1080/00028533.2016.11821868

Gronemeyer, M. E. (2013). La digitalización y sus efectos sobre las prácticas y productos periodísticos en Chile. Palabra Clave, 16(1), 101-128.10.5294/pacla.2013.16.1.4

Hanitzsch, T., \& Hanusch, F. (2012). Does gender determine journalists' professional views? A reassessment based on cross-national evidence. European Journal of Communication, 27(3), 257277. https://doi.org/10.1177/0267323112454804

Iyengar, S (2011). Media politics: A citizen's guide 2nd ed. W.W. Norton.

Jenkins, J., \& Finneman, T. (2018). Gender trouble in the workplace: applying Judith Butler's theory of performativity to news organizations. Feminist Media Studies, 18(2), 157-172. https:// doi.org/10.1080/14680777.2017.1308412

Johnson, D. I. (2005). Feminine style in presidential debate discourse, 1960-2000.

Communication Quarterly, 53(1), 3-20. https://doi.org/10.1080/01463370500055814

Lagos, C., \& Mellado, C. (2013). Chile: Female Journalists Without Access to Power. In The Palgrave International Handbook of Women and Journalism (pp. 226-237). Palgrave Macmillan.

Leiva R, Kimber D. A Persistent Gender Bias in Chilean Press: The Influence of Journalist's Gender and Editor's Gender. Journalism \& Mass Communication Quarterly. https://doi. org/10.1177/1077699020958753

Luengo, O. (2011). Debates electorales en televisión: una aproximación preliminar a sus efectos inmediatos. Revista Española de Ciencia Política, 25, 82-96. https://recyt.fecyt.es/index.php/recp/ article/ view/37516

Maier, J., \& Renner, A. M. (2018). When a Man Meets a Woman: Comparing the Use of Negativity of Male Candidates in Single-and Mixed-Gender Televised Debates. Political Communication, 35(3), 433-449. https://doi.org/10.1080/10584609.2017.1411998

Marín, B. (2003). Debates electorales por televisión, en S. Berrocal (coord.): Comunicación Política en Televisión y Nuevos Medios. Ariel. 
McKinney, M. S., \& Banwart, M. C. (2005). Rocking the youth vote through debate: Examining the effects of a citizen versus journalist controlled debate on civic engagement. Journalism Studies, 6(2), 153-163. https://doi.org/10.1080/14616700500057171

McKinney, M., Rill, L. \& Thorson, E. (2013). Civic Engagement Through Presidential Debates: Young Citizens' Political Attitudes in the 2012 Election. American Behavioral Scientist, 58(6), 755-775. https:// doi.org/10.1177/0002764213515223

McQuail's, D. (2000). Mass communication theory. Thousand Oaks.

Meeks, L. (2013). He wrote, she wrote journalist gender, political office, and campaign news. Journalism \& Mass Communication Quarterly, 90(1), 58-74. https://doi. org/10.1177/1077699012468695

Mellado, C., Salinas, P., Del Valle, C. y González, G. (2010). Estudio comparativo de cuatro regiones: Mercado laboral y perfil del periodista. Cuadernos de Información, 26, pp. 45-64 https:// doi.org/10.7764/cdi.26.1

Mellado, C., Salinas, P., Barría, S. (2010). Estructura del empleo periodístico y validación profesional de sus prácticas en el mercado laboral chileno. INNOVAR. Revista de Ciencias Administrativas y Sociales, 20(36), 91-106. https://www.redalyc.org/articulo. oa?id=818/81819028008

Mullinix, K. (2015). Presidential Debates, Partisan Motivations, and Political Interest. Presidential Studies Quarterly, 45(2), 270-288. https://doi.org/10.1111/psq.12187

North, L. (2016). The Gender of "soft” and "hard” news: Female journalists' views on gendered story allocations. Journalism Studies, 17(3), 356-373. https://doi. org/10.1080/1461670X.2014.987551

Núñez-Mussa, E. (2019). El rol de los periodistas como entrevistadores en los debates presidenciales. En Conde-Vázquez, E., Fontenla-Pedreira, J. y Rúas-Araújo, J. (Eds.), Debates electorales televisados: del antes al después (pp. 129-149). Cuadernos Artesanos de Comunicación, cac 154. La Laguna (Tenerife): Latina. https://doi.org/10.4185/cac154

Peake, L. (1997). Press Coverage of Women Candidates for the UK Parliament. Presented at the ECPR 25th Joint Sessions of Workshops, Universität Bern, Switzerland.

Pellegrini, S., Puente, S., Porath, W., Mujica, C. y Grassau, D. (2011). Valor Agregado Periodístico: La apuesta por la calidad de las noticias. Ediciones Universidad Católica de Chile.

Pérez-Curiel, Concha; García-Gordillo, Mar (2020). Del debate electoral en TV al ciberdebate en Twitter. Encuadres de influencia en las elecciones generales en España (28A). Profesional de la información, 29 (4), 1-18. https://doi.org/10.3145/epi.2020.jul.05

Porath, W., Gunckel, C. O., \& Soto, A. J. R. (2019). The Evolution of the Format of the Presidential Debates on Chilean Television: 1989-2017. A Speciation Case. Comunicación y Sociedad, 1-26. https://doi.org/10.32870/cys.v2019i0.719

Proust, V. (2018). Ironía y descortesía en los debates radiales en Chile: estrategias discursivas para ganar prestigio. Revista Latinoamericana de Estudios del Discurso, 18(2), 93-109. http://dx.doi. org/10.35956/v.18.n2.2018.p.93-109

Rodelo, F. (2016). Disparidades de género en la cobertura mediática de campañas electorales locales en México. Cuadernos.info, (39), 87-99. https://doi.org/10.7764/cdi.39.965 
Ross, K. (2001). Women at work: Journalism as en-gendered practice. Journalism studies, 2(4), 531-544. https://doi.org/10.1080/14616700120086404

Ross, K., \& Carter, C. (2011). Women and news: A long and winding road. Media, Culture \& Society, 33(8), 1148-1165. https://doi.org/10.1177/0163443711418272

Rúas-Araújo, J y Quintas-Froufe, N. (2020). Televisión, audiencias y debates electorales: hacia la multipantalla. El profesional de la información, 29 (2). https://doi.org/10.3145/epi.2020.mar.01

Ruoho, I., \& Torkkola, S. (2018). Journalism and gender: Toward a multidimensional approach. Nordicom Review, 39(1), 67-79. https://doi.org/10.2478/nor-2018-0002

Saks, J., Jordan, L., Hopkins, A. \& El Damanhoury, K. (2016). Dialed In: Continuous Response Measures in Televised Political Debates and Their Effect on viewers. Journal of Broadcasting \& Electronic Media, 60(2), 231-247. https://doi.org/10.1080/08838151.2016.116 4164

Salinas, P., \& Lagos, C. (21-23 de agosto de 2013). Género, discurso crítico y violencia simbólica: El imaginario femenino en la prensa chilena entre el 2006. Actas de la IX Bienal Iberoamericana de Comunicación.

Stange M, H., \& Salinas M, C. (2015). Burocratización de las rutinas profesionales de los periodistas en Chile (1975-2005). Cuadernos.Info, (37), 121-135. https://doi.org/10.7764/ cdi.37.703

Schoch, L. (2013). 'Feminine'writing: the effect of gender on the work of women sports journalists in the Swiss daily press. Media, Culture \& Society, 35(6), 708-723. https://doi. org/10.1177/0163443713491300

Sjøvaag, H. (2010). The reciprocity of journalism's social contract: The political-philosophical foundations of journalistic ideology. Journalism Studies, 11(6), 874-888. https://doi. org/10.1080/14616701003644044

Tuchman, G. 1978. Making News: A Study in the Construction of Reality. New York: The Free Press.

Turcotte, J., \& Goidel, R. K. (2014). Political knowledge and exposure to the 2012 US presidential debates: Does debate format matter?. PS, Political Science \& Politics, 47(2), 449. https://doi.org/10.1017/S1049096514000377

Turcotte, J., \& Paul, N. (2015). A case of more is less: The role of gender in US presidential debates. Political Research Quarterly, 68(4), 773-784. https://doi.org/10.1177/1065912915605581

Van Zoonen, L. (1998). One of the girls?: The changing gender of journalism. En Carter, C., Branston, G. A., \& Allan, S. (Eds. 1998). News, gender and power. Routledge.

Van Zoonen, L. (1988). Rethinking women and the news. European journal of communication, 3(1), 35-53. https://doi.org/10.1177/0267323188003001003

Weischenberg, S. (1992). Die Verantwortung des Beobachters. Moderne Medienethik aus der Perspektive einer konstruktivistischen Systemtheorie. Rundfunk und Fernsehen, 40(4), 507-527. https://doi.org/10.1007/978-3-531-92248-5_16. 
Anexo 1. Tabla resumen: ejemplos de preguntas analizadas

\begin{tabular}{|c|c|c|c|c|}
\hline Ejemplo & Pregunta & Debate & Periodista & Candidato \\
\hline 1 & $\begin{array}{l}\text { A propósito de las mujeres...¿¿Cuántas mujeres ocupan car- } \\
\text { gos de responsabilidad en sus empresas? }\end{array}$ & 2009 & $\begin{array}{l}\text { Catalina } \\
\text { Edwards }\end{array}$ & $\begin{array}{l}\text { Sebastián } \\
\text { Piñera }\end{array}$ \\
\hline 2 & $\begin{array}{l}\text { Revisé su programa y busqué propuestas para la mujer y no } \\
\text { hay un capítulo específico que diga 'propuestas para la mu- } \\
\text { jer', a diferencia de los otros candidatos, pero usted habla } \\
\text { de la extensión del postnatal, del teletrabajo [...] }\end{array}$ & 2009 & $\begin{array}{l}\text { Catalina } \\
\text { Edwards }\end{array}$ & $\begin{array}{l}\text { Marco } \\
\text { Enríquez- } \\
\text { Ominami }\end{array}$ \\
\hline 3 & $\begin{array}{l}\text { La señora Estela Ortiz, viuda de Parada, candidata a dipu- } \\
\text { tada que lo apoya a usted, en condiciones personales de } \\
\text { extremo dolor, ha dicho que se imagina y quiere preso al } \\
\text { general Pinochet ¿Usted también se lo imagina preso? }\end{array}$ & 1989 & $\begin{array}{l}\text { Claudio } \\
\text { Sánchez }\end{array}$ & $\begin{array}{l}\text { Patricio } \\
\text { Aylwin }\end{array}$ \\
\hline 4 & $\begin{array}{l}\text { Señora Miranda, para despejar cualquier duda en torno a } \\
\text { lo que le preguntaba Soledad Onetto, ¿usted legitima o no } \\
\text { legitima la violencia social como herramienta del acceso de } \\
\text { las fuerzas populares al poder? }\end{array}$ & 2013 & $\begin{array}{l}\text { Claudio } \\
\text { Elórtegui }\end{array}$ & $\begin{array}{l}\text { Roxana } \\
\text { Miranda }\end{array}$ \\
\hline 5 & $\begin{array}{l}\text { ¿Un matrimonio igual que el matrimonio heterosexual, con } \\
\text { los mismos derechos, por ejemplo, la posibilidad de adoptar } \\
\text { niños? }\end{array}$ & 2005 & Ivan Núnez & $\begin{array}{l}\text { Tomás } \\
\text { Hirsch }\end{array}$ \\
\hline 6 & $\begin{array}{l}\text { Senador Frei, qué piensa usted cuando lo tratan de Eduar- } \\
\text { dito }\end{array}$ & 1993 & $\begin{array}{l}\text { Jaime } \\
\text { Moreno }\end{array}$ & $\begin{array}{l}\text { Eduardo } \\
\text { Frei }\end{array}$ \\
\hline 7 & $\begin{array}{l}\text { Señor Piñera, usted ha hablado del drama de los trabajado- } \\
\text { res. ¿Usted optaría por impulsar el salario mínimo, que hoy } \\
\text { es de } 123.000 \text { pesos. A un chileno, con los descuentos de } \\
\text { imposiciones, le quedan } 98.000 \text { pesos. De ello un tercio se } \\
\text { va en gasto a movilización. ¿Usted sabe cuánto cuesta el } \\
\text { nuevo transporte, bonito ese, del Transantiago, cuánto es el } \\
\text { valor que cuesta? }\end{array}$ & 2005 & $\begin{array}{l}\text { Libardo } \\
\text { Buitrago }\end{array}$ & $\begin{array}{l}\text { Sebastián } \\
\text { Piñera }\end{array}$ \\
\hline 8 & $\begin{array}{l}\text { Usted ha señalado que eh... Se requiere dignificar la polí- } \\
\text { tica. Pero ¿se logra esto cuando usted trata, por ejemplo, } \\
\text { a las mujeres de sus contendores como "escorts" o bien el } \\
\text { comando o representantes de su comando, y usted particu- } \\
\text { larmente, como conejitas playboy? ¿Se dignifica la política? }\end{array}$ & 2013 & $\begin{array}{l}\text { Claudio } \\
\text { Elórtegui }\end{array}$ & $\begin{array}{l}\text { Tomás } \\
\text { Jocelyn- } \\
\text { Holt }\end{array}$ \\
\hline 9 & $\begin{array}{l}\text { Señor Guillier, anoche en un programa de televisión -ya } \\
\text { lo comentó- habló de un spot que usted hizo el } 2006 \text { expli- } \\
\text { cando las cualidades de las isapres, dijo que en ese tiempo } \\
\text { estaba convencido que eran buenas pero que después } \\
\text { quitaron beneficios y comenzaron con los abusos, pero para } \\
\text { esa fecha usted ya había sido conductor de noticias, direc- } \\
\text { tor de prensa, estuvo en Tolerancia Cero, presentó Informe } \\
\text { Especial ¿No escuchó nunca hablar de la discriminación de } \\
\text { los planes de la mujeres, de las preexistencias, de las alzas } \\
\text { unilaterales? }\end{array}$ & 2017 & $\begin{array}{l}\text { Ramón } \\
\text { Ulloa }\end{array}$ & $\begin{array}{l}\text { Alejandro } \\
\text { Guillier }\end{array}$ \\
\hline 10 & $\begin{array}{l}\text { Usted ha dicho que se pueden ahorrar } 7 \text { mil millones de } \\
\text { dólares sacando lo que usted ha denominado "la grasa del } \\
\text { Estado", algo que el ministro Nicolás Eyzaguirre le debatió } \\
\text { ayer a través de la prensa diciendo coloquialmente "cuénta- } \\
\text { me una de vaqueros" pero lo cierto es que en el análisis de } \\
\text { los expertos y los economistas ese monto no se logra si es } \\
\text { que solo se recortar viáticos o gastos menores. La pregunta } \\
\text { es muy concreta ¿Cuáles son los programas que se van a } \\
\text { eliminar para obtener este ahorro de } 7 \text { mil millones? }\end{array}$ & 2017 & $\begin{array}{l}\text { Soledad } \\
\text { Onetto }\end{array}$ & $\begin{array}{l}\text { Sebastián } \\
\text { Piñera }\end{array}$ \\
\hline
\end{tabular}




\begin{tabular}{|c|c|c|c|c|}
\hline 11 & $\begin{array}{l}\text { Marcel Claude, usted en otras entrevistas ha calificado el } \\
\text { lucro ni siquiera como un valor humano, es un desvalor, } \\
\text { ha dicho...¿Por qué le molesta tanto el lucro? ¿Qué le dice } \\
\text { por ejemplo a los pequeños y medianos empresarios que } \\
\text { lo están escuchando esta noche, que legítimamente hacen } \\
\text { su negocio con el objetivo de obtener alguna ganancia, de } \\
\text { obtener lucro? }\end{array}$ & 2013 & $\begin{array}{c}\text { Mauricio } \\
\text { Bustamante }\end{array}$ & $\begin{array}{l}\text { Marcel } \\
\text { Claude }\end{array}$ \\
\hline 12 & $\begin{array}{l}\text { Señora Matthei, emm... según la encuesta del CEP el } 74 \% \\
\text { de la gente quiere educación gratis. Es el dato duro que en- } \\
\text { tregó hace poco el estudio. Usted ha reiterado que está en } \\
\text { contra porque lo considera regresivo. En esa misma encues- } \\
\text { ta usted está, además, al borde de perder en primera vuelta } \\
\text { esta elección. Me gustaría saber si usted está dispuesta a } \\
\text { decirle que no en esta materia a } 3 \text { de } 4 \text { chilenos. }\end{array}$ & 2013 & Iván Núñez & $\begin{array}{l}\text { Evelyn } \\
\text { Matthei }\end{array}$ \\
\hline 13 & $\begin{array}{l}\text { Señor Enríquez Ominami, volvamos a la CEP, son los datos } \\
\text { más actuales que tenemos. } 83 \% \text { está por nacionalizar el co- } \\
\text { bre, tema de importancia para la opinión pública. Usted hace } \\
\text { cuatro años propuso abrir parte de Codelco a la Bolsa, ¿no } \\
\text { es así? Hoy habla de nacionalizar los recursos naturales. } \\
\text { Asumiendo que todos tenemos derecho a cambiar de opi- } \\
\text { nión, ¿qué pasó en el camino? ¿Por qué cambió de opinión? }\end{array}$ & 2013 & $\begin{array}{l}\text { Soledad } \\
\text { Onetto }\end{array}$ & $\begin{array}{c}\text { Marco } \\
\text { Enríquez- } \\
\text { Ominami }\end{array}$ \\
\hline
\end{tabular}

